\title{
The influence of nursing home managers' leadership on person-centred care and stress of conscience: A cross-sectional study
}

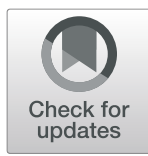

Annica Backman ${ }^{1 *}$, Karin Sjögren ${ }^{1}$, Hugo Lövheim², Marie Lindkvist ${ }^{3}$ and David Edvardsson ${ }^{1,4}$

\begin{abstract}
Background: Leadership and stress are common concepts in nursing, and this study explores empirically the connection between leadership and stress of conscience in the context of aged care practice. Previous literature has shown that when staff are unable to carry out their ethical liabilities towards the residents, feelings of guilt may occur among staff, which may be an expression of stress of conscience. Although leadership has been described as crucial for staff's work perceptions of stress as well as for person-centred practices, the influence of nursing home managers' leadership on stress of conscience among staff and person-centred practices is still not fully explored. This study attempts to address that knowledge gap by exploring the relationship between leadership, personcentred care, and stress of conscience.
\end{abstract}

Methods: This study was based on a cross-sectional national survey of 2985 staff and their managers in 190 nursing homes throughout Sweden. Descriptive statistics and regression modelling were used to explore associations.

Results: Leadership was associated with a higher degree of person-centred care and less stress of conscience. A higher degree of person-centred care was also associated with less stress of conscience. The results also showed that leadership as well as person-centred care were individually associated with lower levels of stress of conscience when adjusting for potential confounders.

Conclusion: Nursing home managers' leadership was significantly associated with less staff stress of conscience and more person-centred care. This indicates that a leadership most prominently characterised by coaching and giving feedback, relying on staff and handling conflicts constructively, experimenting with new ideas, and controlling work individually can contribute to less staff stress as well as higher degree of person-centred care provision.

Keywords: Leadership, Management, Person-centred care, Stress of conscience

\section{Background}

Previous research has shown that nursing home care services are physically and emotionally challenging with ethical dilemmas and conflicting demands in daily care [1-3]. The prevalence of stress-related illnesses among

\footnotetext{
* Correspondence: annica.backman@umu.se

'Department of Nursing, Umeå University, SE-901 87 Umeå, Sweden

Full list of author information is available at the end of the article
}

nursing home care staff has increased during the last decades $[4,5]$. On a daily basis, many care situations contain ethically difficult issues and challenges for care staff [6]. Experiences of not being able to fulfil ethical obligations to residents commonly lead to feelings of guilt and stress of conscience [7-9]. Although leadership has been advocated as a key component for staff perceptions of work stress as well as for person-centred care, the

(c) The Author(s). 2021 Open Access This article is licensed under a Creative Commons Attribution 4.0 International License, which permits use, sharing, adaptation, distribution and reproduction in any medium or format, as long as you give appropriate credit to the original author(s) and the source, provide a link to the Creative Commons licence, and indicate if changes were made. The images or other third party material in this article are included in the article's Creative Commons licence, unless indicated otherwise in a credit line to the material. If material is not included in the article's Creative Commons licence and your intended use is not permitted by statutory regulation or exceeds the permitted use, you will need to obtain permission directly from the copyright holder. To view a copy of this licence, visit http://creativecommons.org/licenses/by/4.0/ The Creative Commons Public Domain Dedication waiver (http://creativecommons.org/publicdomain/zero/1.0/) applies to the data made available in this article, unless otherwise stated in a credit line to the data. 
impact of nursing home managers' leadership on levels of stress of conscience are yet to be explored.

In care, nursing home staff balance the ideals and ethical values with the various and sometimes incompatible demands from residents, colleagues, superiors, and organisations [7]. Ethical challenges such as dissonance between residents' autonomy and a fair and equal resource distribution while still fulfilling organisational demands have been reported as a source to stress in nursing homes [6]. A troubled conscience has been described to occur when direct care staff perceive being unable to do "good" in care, or when they are not able to provide care that corresponds to their ethical values [7]. The concept "Stress of conscience" captures the stress that is generated by a troubled conscience $[9,10]$. Lower levels of person-centred care have been associated with higher levels of stress of conscience among nursing home staff [11]. Negative effects of stress of conscience have been well documented with associations with high levels of emotional exhaustion and burnout among staff $[12,13]$, sleeping problems, and depressive symptoms [14].

Person-centred care has increasingly been promoted as the recommended humanistic model of care that has been adopted by policy-makers, researchers, nursing curriculums, and practitioners due to the ethical underpinnings and emerging evidence of positive effects on residents [15-17] and staff $[11,18]$. Person-centred care proposes a humanistic philosophy and ethical values for maintaining the person's personhood despite illness and integrating the persons wishes and preferences by using personal experiences to individualise both the care and the environment [19]. It seems reasonable to hypothesise that providing person-centred care could reduce perceptions of stress of conscience because providing personcentred care with an emphasis on residents' wishes and needs would seem to correspond well with common humanistic ethical values and staff ambitions to do good for vulnerable residents. This can in turn be linked to less experiences of stress of conscience. Previous crosssectional studies have reported that a higher degree of person-centred care is associated with lower levels of stress of conscience [11, 14]. However, a recent multicentre person-centred intervention study showed no effect on stress of conscience after the intervention. One interpretation by the authors was that the lack of effect was partly due to absent leadership support during the intervention as well as a limited focus on stress of conscience per se [20]. The importance of nursing home managers' leadership for the implementation of personcentred care has been established by previous research [21-26], as well as the central role of leaders in developing and supporting person-centred care practices in everyday care [27-29]. However, the extent to which leadership is associated with direct care staff experiences of stress of conscience has received limited attention in the literature. Only one study was found that reported a high level of person-centred care and positive leadership as contributing to low stress of conscience among nursing home staff, and that study concluded that leadership support was needed for reducing staff stress of conscience and for enabling personalised care provision [14]. This indicates that leadership may be of significance for both perceptions of stress of conscience and for the extent to which staff are able to provide personcentred care, but existing empirical data are limited, suggesting a need for further research. This study attempts to address this gap in the literature by exploring relationships between leadership, person-centred care, and stress of conscience as perceived by direct care staff.

\section{Method}

\section{Design and sampling}

The present study is based on data from a project with a repeated cross-sectional design, the Swedish National Inventory of Care and Health in Residential Aged Care (SWENIS), carried out within the Umeå Aging and Health Research Programme (U-AGE), [30]. The U-Age SWENIS study uses a repeated cross-sectional design for longitudinal monitoring of health and care in Swedish nursing homes. This study draws solely on SWENIS II data from the follow-up in 2018-2019. The SWENIS II sample consists of data from 43 municipalities (28 baseline and 15 new) contributing with organisational, staff, and resident data from 190 nursing homes.

\section{Study context}

There are approximately 2300 nursing homes in Sweden with approximately 82,000 residents. Nursing homes in Sweden are defined as a specialised form of housing for older people aged 65 years or older who have comprehensive needs for medical care and/or personal care as a result of physical and/or cognitive impairment [31, 32]. The size of the nursing homes in this study ranged between 6 and 116 beds with a mean of 40 beds (SD 18.4) (median 36). Participating units included both general nursing home units (68\%) and special care units for people with dementia (32\%). Approximately $85 \%$ of the nursing homes were run by public providers, while $15 \%$ had private providers.

\section{Data collection}

For the purposes of this study, data from two surveys within the SWENIS II were used. The first survey was directed to staff and comprised staff demographic variables (age, gender, native language, educational qualifications, work shift, years of experience in aged care, and years of experience in the current facility). The first survey also asked about staffs' estimations of leadership, 
person-centred care, and stress of conscience. The second survey was directed to managers and comprised demographics (age, gender, work experience, and educational qualification) of managers of the included nursing homes (Table 1). The initial step was to obtain consent to conduct the study from the chief executive officer in each municipality. When consent was obtained, the

Table 1 Characteristics of the sample staff $n=2985$ and managers $n=214$

\begin{tabular}{|c|c|c|}
\hline Staff & $\mathrm{n}^{\mathrm{a}}(\%)$ & m (SD) \\
\hline Age (Years) & & $45.4(12.3)$ \\
\hline \multicolumn{3}{|l|}{ Gender } \\
\hline Men & $202(6.8)$ & \\
\hline Women & $2770(93.2)$ & \\
\hline \multicolumn{3}{|l|}{ Native language } \\
\hline Swedish & $2313(82.6)$ & \\
\hline Other & $487(17.4)$ & \\
\hline \multicolumn{3}{|l|}{ Qualifications } \\
\hline Registered nurses & $24(0.8)$ & \\
\hline Enrolled nurses & $2534(85.5)$ & \\
\hline Nurse's assistants & $296(10.0)$ & \\
\hline No formal qualifications & $72(2.4)$ & \\
\hline Other education & $37(1.2)$ & \\
\hline \multicolumn{3}{|l|}{ Work shift } \\
\hline Day shift & $74(2.5)$ & \\
\hline Day and evening & $2563(85.9)$ & \\
\hline Day, evening, night shift & $304(10.2)$ & \\
\hline Years of experience in aged care & & $17.2(11.8)$ \\
\hline Years of experience in this facility & & $9.6(8.7)$ \\
\hline Managers & $n^{b} \%$ & $\mathrm{~m}(\mathrm{SD})$ \\
\hline Age (Years) & & $50.6(9.9)$ \\
\hline \multicolumn{3}{|l|}{ Gender } \\
\hline Men & $19(8.9)$ & \\
\hline Women & $195(91.1)$ & \\
\hline \multicolumn{3}{|l|}{ Qualifications } \\
\hline Human resource specialist & $14(6.5)$ & \\
\hline Registered nurses & $54(25.2)$ & \\
\hline Enrolled nurses & $31(14.5)$ & \\
\hline Social work & 89 (41.6) & \\
\hline Other education & $26(12.1)$ & \\
\hline \multicolumn{3}{|l|}{ Leadership education } \\
\hline National leadership education 30 ECTS & $23(15.6)$ & \\
\hline Other leadership education & $124(84.4)$ & \\
\hline Years of experience as a manager & & $12.7(9.0)$ \\
\hline Years of experience in this facility & & $4.6(4.6)$ \\
\hline
\end{tabular}

${ }^{a} \mathrm{n}$ does not always add up to 2985 in all variables due to missing items

${ }^{b} \mathrm{n}$ does not always add up to 214 in all variables due to missing items nursing home managers in the invited nursing homes were telephoned and verbal information was given and an e-mail was sent to the nursing home managers with written information about the study. The anonymous surveys were handed out to staff by their nursing home managers. Every completed staff survey was returned in a sealed envelope to safeguard staffs' confidentiality. The organisational survey was completed by the nursing home managers through a structured telephone interview. One inclusion criterion was that staff needed to have long-term substitution or permanent employment and work daytime or day/evening shifts to be eligible for inclusion. A total of 5803 surveys were distributed in SWENIS II. After removing blank surveys and those that were answered by staff who solely worked night-time, the final sample consisted of 2985 staff (response rate $=$ $52 \%)$. The data collection was performed during a 6month period between November 2018 and April 2019.

\section{Instrumentation \\ Leadership behaviour questionnaire}

The Leadership Behaviour Questionnaire was used to investigate leadership and the extent to which direct care staff perceived that their manager expressed a range of behaviours facilitating this [33, 34]. The Leadership Behaviour Questionnaire consists of 24 items formulated as statements about leadership behaviours, where higher scores indicate leadership behaviours that facilitate efficient service delivery [33, 34]. Staff were asked to rate their manager/leader on a six-point scale from 1 , completely disagree, to 6 , completely agree. A total score can be calculated with a possible range of 24-144 [14]. The Leadership Behaviour Questionnaire has been tested in Swedish aged care contexts in previous research, and the confirmatory factor analysis suggested a unidimensional factor structure with a reliability $\alpha=0.98$ [28]. Based on this, the scale has been further explored with a twoparameter item response theory approach to identify the measured leadership characteristics. The most significant behaviours of managers with the highest leadership sum scores were Experiments with new ideas, Controls work closely, Relies on his/her subordinates, and Coaches and gives direct feedback followed by Handles conflicts in a constructive way [29]. This was interpreted as representing the five most important characteristics of leadership behaviours in nursing homes, were higher scores are favourable. The 24-item questionnaire and its previous psychometric testing is further described in [29, 33, 34]. Cronbach's $\alpha=0.98$ in this sample.

\section{Person-centred care assessment tool}

The P-CAT is a self-reported assessment scale that measures the extent to which staff perceive the care provided to be person-centred $[35,36]$. The P-CAT consists of 13 
items formulated as statements about the content of care and aspects of the environment and the organisation. Staff are asked to rate the items on a five-point scale ranging from 1 , disagree completely, to 5 , agree completely, and a total score is calculated (range 13-65) with higher values indicating a higher degree of personcentred care. The Swedish version of the P-CAT has shown satisfactory estimates of reliability (Cronbach's $\alpha=0.75)$ and construct validity in Swedish aged care [36]. Cronbach's $\alpha=0.77$ in this sample.

\section{Stress of conscience}

The Stress of Conscience Questionnaire assesses stress related to troubled conscience among staff [10]. Stress of conscience arises when staff experience intrapersonal conflicts in relation to a person's basic values and their views of what is right or wrong and what is good or bad. The questionnaire contains two parts, A and B. Part A comprises nine items and focuses on how often a certain stressful care situation is perceived to occur in the participant's workplace, with the response alternatives 'never' (0), 'less than once/six months' (1), 'more than once/six months' (2), 'every month' (3), 'every week' (4), and 'every day' (5). Each item in part A is followed by a $B$ question concerning the degree of troubled conscience each specific situation evokes. A continuous variable can be calculated as a measure of stress of conscience by multiplying part $\mathrm{A}$ of an item (how often a certain situation is perceived) with part $B$ of the same item (level of troubled conscience the situation evokes). The scores of $\mathrm{A}$ and $\mathrm{B}$ are multiplied to reflect the total "stress of conscience" for each item. Adding the scores of all items gives a total score with a possible range of between 0 and 225, where higher scores indicate more stress of conscience. The questionnaire is validated for Swedish conditions, and satisfactory psychometric properties have been reported [10]. Cronbach's $\alpha=0.90$ for whole scale $(\mathrm{A}+\mathrm{B})$ in this sample, and $\alpha=0.81$ for the A part, and $\alpha=0.85$ for the B part.

\section{Analyses}

SPSS statistics version 26 was used to analyse the data. Missing items in the questionnaires were imputed with the mean value of the individual for the whole scale. Up to three missing items were replaced in the Leadership Behaviour Questionnaire, (missing $<10.4 \%$ of data). For the P-CAT, up to two items were replaced (missing $<7.7 \%$ of data) and for Stress of Conscience Questionnaire up to one item was replaced (missing $<7.1 \%$ of data) (cf. [37]).

The tolerance coefficient of 0.9 and VIF coefficient of 1.1 were not found to violate the prerequisites for multicollinearity (cf. [38]). No correlation between the scales exceeded $r=0.5$. The data were checked for potential interaction patterns, and no significant interactions between study variables were discovered. Cronbach's alpha was used to explore the reliability of all included scales. $P$-values of $<0.05$ were regarded as statistically significant, and staff demographic variables (aged, gender, educational qualifications, work shift, and years of experience in aged care and in the current facility) were used for presenting characteristics of the study participants (Table 1) and for controlling for confounders in regression analyses. Managers' demographics (age, gender, work experience, and educational qualification) and organisational characteristics' such as operational form, type of setting, and number of beds were used to report characteristics of the managers and the nursing homes and for controlling for confounders in regression analyses.

As a first step, descriptive and comparative statistics were used to explore mean values, standard deviations, and the sample characteristics. As a second step, the correlation between the main study variables was explored by using Pearson's product-moment correlations. As a third step, a multiple regression analysis was conducted to explore the relationship between leadership, person-centred care, and stress of conscience, with stress of conscience as a dependent variable (adjusted for staff gender, age, education, years of experience in aged care, years of experience in the nursing home, type of facility, operational form, and number of beds per facility). Finally, due to the fact that individuals were correlated in units, e.g. staff rated their perception of practice within the unit, an exchangeable correlation structure was assumed and the parameters were thereby estimated by using Generalised Estimating Equations (GEE) using care unit as the subject variable and stress of conscience as the dependent variable.

\section{Results}

The majority of the participating staff were women $(93.2 \%)$ with a mean age of 45.4 years $(\mathrm{SD} \pm 12.3)$. Most participating staff were enrolled nurses $(85.5 \%)$ with a median work experience within aged care of 17.2 years ( $\mathrm{SD} \pm 11.8)$. Most staff had Swedish as their native language. The majority of the managers were women $(91.1 \%)$ with a mean age of 50.6 years $(\mathrm{SD} \pm 9.9)$. They had on average 12.7 years of work experience in aged care $(\mathrm{SD} \pm 9.0)$ and around 4.6 years $(\mathrm{SD} \pm 4.6)$ of work experience in their current nursing home. The majority of the managers had a degree in social work (41.6\%), followed by registered nursing (25.2\%) and enrolled nursing (14.5\%) qualifications. About $12.1 \%$ of the managers had other education (Table 1).

Leadership and person-centredness of care showed a significant positive correlation $(r=0.42, p<0.001)$. There was also a significant negative correlation between leadership and stress of conscience $(r=-0.32, p<0.001)$. A 
significant and negative correlation was also found between person-centred care and stress of conscience $(r=$ $-0.49, p<0.001)$. For mean values of leadership, personcentred care, and stress of conscience and their correlations, see Table 2.

In the multiple regression analysis, leadership $(\beta=-$ $0.22, p<0.001$ ) and person-centred care (st $\beta=-.2 .319$, $p<0.001)$ were significantly related to a lower level of perceived stress of conscience. The model was adjusted for potential confounders, including staff gender, age, education, years of experience in aged care, years of experience in the nursing home, type of facility, operational form, and number of beds per facility. The multiple regression model explained $28.5 \%$ of the variance in stress of conscience (Table 3). The GEE showed similar results, that leadership $(\beta=-0.224, p<0.001)$ and person-centred care $(\beta=-.2197, p<0.001)$ were significantly related to lower level of perceived stress of conscience, even when taking into account that individuals were correlated in units and adjusting for staff gender, age, education, years of experience in aged care, years of experience in the nursing home, type of facility, operational form, and number of beds per facility.

\section{Discussion}

This study aimed to explore relationships between leadership, person-centred care, and stress of conscience as perceived by direct care staff. The results showed that leadership was associated with higher ratings of personcentred care and lower perceived stress of conscience. Higher ratings of person-centred care were also associated with lower perceived stress of conscience. The results also showed that leadership as well as personcentred care were individually associated with lower levels of stress of conscience in the multiple regression models when adjusting for potential confounders. This indicates that leadership most prominently characterised by coaching and giving feedback, relying on staff, handling conflicts constructively, experimenting with new ideas, and controlling work individually may contribute to less staff stress of conscience, even when adjusted for person-centred care. This has some potential clinical implications for nursing managers who may be in a position to use these leadership behaviours in their own

Table 2 Mean values and correlations of study variables

\begin{tabular}{lllll}
\hline & M (sd) & $\boldsymbol{r}$ & $\boldsymbol{r}$ & $\boldsymbol{r}$ \\
& & Leadership & SCQ & P-CAT \\
\hline Leadership & $112.1(22.8)$ & & & \\
SCQ & $41.5(37.0)$ & $-0.32^{\mathrm{a}}$ & & \\
P-CAT & $50.8(7.3)$ & $0.42^{\mathrm{a}}$ & $-0.49^{\mathrm{a}}$ & \\
\hline
\end{tabular}

SCQ Stress of Conscience Questionnaire

$P$-CAT Person-centred Care Assessment Tool

${ }^{a}$ Correlation is significant at the 0.01 level (2-tailed) practice to influence person-centred care and to reduce staff stress of conscience. Because there was a positive correlation between leadership and person-centred care, this can also be interpreted as meaning that leadership has an impact on staff stress of conscience partly by positively influencing the provision of person-centred care. This can be interpreted to mean that managers might be able to further promote person-centred care by using the leadership behaviours of trusting staff, delegating responsibility, encouraging thinking along new lines, and discussing and encouraging new ideas. Orrung Wallin et al. [14] also using the same leadership scale showed that these leadership dimensions are important for staff's perception of stress of conscience, and this current study supports their findings.

Direct care staff in nursing homes might be confronted with ethical dilemmas in their daily work and are sometimes left alone in these difficult choices and decision-making, thus potentially bringing a burdensome and mentally demanding work situation [39]. Although a conscience can be perceived as an asset, a warning signal that makes you act in accordance with your moral values [40], feelings of powerlessness and inadequacy may occur when the conscience is constantly challenged when striving to be and do "good enough" in your work [41]. Previous research has shown that the perception of stress of conscience can arise if and when limited support and leadership are perceived from managers, and this is why leadership seems to play an important role for perceived stress of conscience [7]. It has been stated that staff need opportunities to discuss conflicting feelings to be able to cope with the consequences that follow a troubled conscience [7], and by sharing experiences with others an agreement in the work group on what can be seen as reasonable goals and requirements in daily care can be achieved [42, 43]. Seen in relation to this study's findings, where nursing home managers' leadership significantly impacts levels of stress of conscience among staff, an important implication for managers seems to be to facilitate ethical discussions so that staff can achieve a balance between conflicting demands and can discuss what can be considered as realistic measures in everyday care. Previous research has shown that staff who have to deaden their conscience to be able to work and simultaneously perceive low support are at risk for burnout [43], giving further support for the centrality of leadership and support. A previous study has also pointed out that a manager needs to identify and handle organisational factors that are ethically relevant, especially when these contradict the staff's value standards [44]. This indicates that nursing home managers need to reflect upon the organisational context within nursing homes, and recognize when there is a mismatch between care needed and care provided, and 
Table 3 Multiple linear regression model explaining the variance of stress of conscience

\begin{tabular}{|c|c|c|c|c|c|c|}
\hline & \multicolumn{3}{|c|}{ Linear regression $^{\mathrm{a}}$} & \multicolumn{3}{|l|}{$\mathrm{GEE}^{\mathrm{a}, \mathrm{b}}$} \\
\hline & $\beta$ & Std. Error & $p$-value & $\beta$ & Std. Error & $p$-value \\
\hline Leadership & -0.220 & 0.032 & $<0.001$ & -0.224 & 0.0386 & $<0.001$ \\
\hline Person-centred care & -2.319 & 0.100 & $<0.001$ & -2.197 & 0.1171 & $<0.001$ \\
\hline Dependent variable: Stress of conscience & \multicolumn{6}{|c|}{ Adjusted R-Square 28.5\% } \\
\hline
\end{tabular}

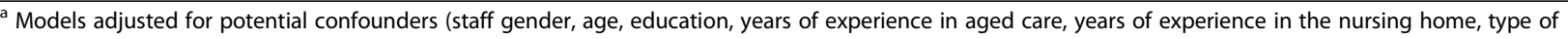
facility, operational form, and number of beds per facility)

${ }^{\mathrm{b}}$ GEE Generalized Estimating Equations

assist managing these dilemmas, as this has significance on staff perception of stress of conscience. One important implication for policy makers and stakeholders is to consider the range and complexity of conflicting ethical principles that staff encounter in their daily work, and provide support and resources for regular team reflections', so that diverse perspectives can brought up for open discussion as a strategy to mitigate stress of conscience among staff.

The results in the current study also showed that a higher degree of person-centred care was associated with lower levels of stress of conscience. This is consistent with previous research $[11,45]$ suggesting that working in a person-centred manner may mean providing care in line with one's intrinsic values and one's own perceptions of "good care". This is further supported by intervention research by Edvardsson et al. [46] where "doing good" for residents (i.e. providing the care and activities as wanted/whished) reduced perceptions of stress of conscience among staff. This in turn has implications on staff intentions to leave the field because lack of support, appreciation, and resources hinders staff in providing care as they wish to, which contributes to staff turnover in nursing homes [47]. The findings of this study also revealed a significant association between leadership and person-centred care, highlighting the importance of nursing home managers' leadership because this can be interpreted as leadership having a direct impact on staff stress of conscience, but also an indirect impact through influencing the development of person-centred care provision. This implies that nursing home managers have an important leadership role in inspiring and making it possible for staff to be able to provide care that is based on residents' needs and preferences because "doing good" not only enables high-quality care, but also soothes and relieves the conscience among staff. Previous research has suggested that the Stress of Conscience Questionnaire can be a significantly helpful tool for clinical managers in this process [48]. This study is novel and adds some empirical evidence for how leadership is associated with staff stress of conscience and personcentred care, something which has only sparsely been empirically investigated previously. This study provides insights that a leadership most prominently characterised by behaviours such as experimenting with new ideas, controlling work closely, relying on his/her subordinates, coaching and giving direct feedback, and handling conflicts in a constructive way is positively associated with less staff stress of conscience as well as with increased person-centred care. In terms of practical implications, this suggests that managers can employ these concrete behaviours as a means to improve the person-centredness of care and to mitigate the workforce risks and consequences of staff stress of conscience.

\section{Limitations}

This study is based on self-rated cross-sectional data from staff, which means that inferences about causality are not possible. However, the direction of analyses was based on previous theoretical hypotheses lending support for the analyses that were used. Still, subsequent longitudinal and interventional studies are recommended. This study draws on data from the Swedish aged care context, and it remains unknown whether or not the results would differ if other participants in other nursing contexts responded to the survey. However, this study is based on extensive cross-sectional randomised follow-up data from a national representative sample of staff in Swedish nursing homes, which suggests that the results might be applicable across similar contexts, but we leave it to the reader to make this judgement of transferability. The regression models explained $28 \%$ of the variance in stress of conscience in a linear regression model when including the demographic variables of the organisation. This suggests that there are other unknown factors that can contribute to explaining stress of conscience among staff in nursing home care. This suggests that further research is needed to explore additional factors, for example, staff workload, preparedness to handle and cope with difficult ethical situations, etc. Further international comparative and interventional studies would be valuable in confirming or rejecting these findings and in exploring the trajectories and interventions that might promote leadership in nursing home care and the associated stress of conscience and person-centred care. 


\section{Conclusion}

This study provides important measures of leadership in nursing home care and its significance for stress of conscience and degree of person-centred care. The results show that nursing home managers' leadership is significantly correlated to less staff stress of conscience and more person-centred care provision. This indicates that a leadership most prominently characterised by coaching and giving feedback, relying on staff, handling conflicts constructively, experimenting with new ideas, and controlling work individually can contribute to less staff stress as well as increased person-centred care provision. This can be interpreted to mean that nursing home managers have an important leadership role in inspiring and enabling staff to provide person-centred care that is based on residents' needs and preferences and that this may, in addition to improving ethical, humanistic, and high quality care as shown in other studies, also lessen the stress of conscience in direct care staff.

\section{Abbreviations}

OECD: Organisation for Economic Co-operation and Development; NBHW: National Board of Health and Welfare; P-CAT: The Person-centred Care Assessment Tool; SCQ: Stress of conscience

\section{Acknowledgements \\ The authors would like to thank nursing home managers and staff for participating in the study.}

\section{Authors' contributions}

All authors ( $A B, K S, M L, H L$ and $D E$ ) participated in the conception and design of the study and in the analysis and interpretation of the data. $A B$ contributed to data collection. $\mathrm{AB}, \mathrm{KS}, \mathrm{ML}, \mathrm{HL}$, and DE drafted the manuscript or critically revised it for important intellectual content. All authors approved the final manuscript.

\section{Funding}

This study was funded by Varrdalstiftelsen, the Swedish Research Council for Health, Working Life and Welfare (2014-4016), and Swedish Research Council (521-2014-2715). The funding organisations had no role in the design or execution of the study or in data collection, analyses, or interpretation or in the preparation, review, or approval of the submitted manuscript. The Open Access fee was funded by the Umeå University.

\section{Availability of data and materials}

The datasets analysed in the current study available from corresponding author on reasonable request.

\section{Declarations}

\section{Ethics approval and consent to participate}

Ethical approval was received from the Regional Ethical Review Board in Umea (Dnr Ö 20-2018), and all methods were carried out in accordance with relevant guidelines and regulations. All participants received written information about the study, including information that it was voluntary to participate and that they could withdraw their participation at any time with no further explanations. Completing and returning the survey was considered to be consent to participate.

\section{Consent for publication}

Not applicable.

\section{Competing interests}

The authors declare no competing interests.

\section{Author details}

'Department of Nursing, Umeå University, SE-901 87 Umeå, Sweden. 2Department of Community Medicine and Rehabilitation, Umeå University, Umeå, Sweden. ${ }^{3}$ Epidemiology and Global Health, Umeå University, Umeå, Sweden. ${ }^{4}$ School of Nursing and Midwifery, La Trobe University, Melbourne, Australia.

Received: 22 February 2021 Accepted: 29 September 2021

Published online: 15 October 2021

\section{References}

1. Edberg A, Edberg A, Bird M, Richards DA, Woods R, Keeley P, et al. Strain in nursing care of people with dementia: nursers' experience in Australia, Sweden and United Kingdom. Aging Ment Health. 2008;12(2):236-43.

2. Edvardsson D, Sandman PO, Nay R, Karlsson S. Predictors of job strain in residential dementia care nursing staff. J Nurs Manag. 2009;17(1):59-65.

3. Hazelhof T, Schoonhoven L, van Gaal B, Koopmans R, Gerritsen D. Nursing staff stress from challenging behaviour of residents with dementia: a concept analysis. Int Nurs Rev. 2016;63(3):507-16.

4. OECD. Who Cares? Attracting and Retaining Care Workers for the Elderly. Paris: OECD Health Policy Studies, OECD Publishing; 2020. https://doi.org/1 0.1787/92c0ef68-en. Accessed 20 Nov 2020

5. Zhang $Y$, Punnett L, Mawn B, Gore R. Working conditions and mental health of nursing staff in nursing homes. Issues Ment Health Nurs. 2016;37(7):48592.

6. Preshaw DH, Brazil K, McLaughlin D, Frolic A. Ethical issues experienced by healthcare workers in nursing homes: literature review. Nurs Ethics. 2016; 23(5):490-506.

7. Glasberg AL, Eriksson S, Norberg A. Factors associated with 'stress of conscience'in healthcare. Scand J Caring Sci. 2008;22(2):249-58.

8. Juthberg C, Eriksson S, Norberg A, Sundin K. Perceptions of conscience in relation to stress of conscience. Nurs Ethics. 2007;14(3):329-43.

9. Åhlin J, Ericson-Lidman E, Eriksson S, Norberg A, Strandberg G. Longitudinal relationships between stress of conscience and concepts of importance. Nurs Ethics. 2013;20(8):927-42.

10. Glasberg A-L, Eriksson S, Dahlqvist V, Lindahl E, Strandberg G, Söderberg A, et al. Development and initial validation of the stress of conscience questionnaire. Nurs Ethics. 2006;13(6):633-48.

11. Sjögren $K$, Lindkvist M, Sandman PO, Zingmark K, Edvardsson D. To what extent is the work environment of staff related to person-centred care? A cross-sectional study of residential aged care. J Clin Nurs. 2014;24(9-10): 1310-9.

12. Åhlin J, Ericson-Lidman E, Norberg A, Strandberg G. A comparison of assessments and relationships of stress of conscience, perceptions of conscience, burnout and social support between healthcare personnel working at two different organizations for care of older people. Scand J Caring Sci. 2015;29(2):277-87.

13. Juthberg C, Eriksson S, Norberg A, Sundin K. Perceptions of conscience, stress of conscience and burnout among nursing staff in residential elder care. J Adv Nurs. 2010;66(8):1708-18.

14. Orrung Wallin A, Jakobsson U, Edberg A-K. Job strain and stress of conscience among nurse assistants working in residential care. J Nurs Manag. 2015;23(3):368-79.

15. Chenoweth L, King MT, Jeon $Y H$. Caring for aged dementia care resident study (CADRES) of person-centred care, dementia-care mapping, and usual care in dementia: a cluster-randomised trial (vol 8, pg 317, 2009). Lancet Neurol. 2009;8(4):317-25.

16. Rokstad AMM, Rosvik J, Kirkevold O, Selbaek G, Benth JS, Engedal K. The effect of person-Centred dementia care to prevent agitation and other neuropsychiatric symptoms and enhance quality of life in nursing home patients: a 10-month randomized controlled trial. Dement Geriatr Cogn. 2013;36(5-6):340-53.

17. Sjögren K, Lindkvist M, Sandman PO, Zingmark K, Edvardsson D. Personcentredness and its association with resident well-being in dementia care units. J Adv Nurs. 2013;69(10):2196-206.

18. Wallin AO, Jakobsson U, Edberg AK. Job satisfaction and associated variables among nurse assistants working in residential care. Int Psychoger. 2012; 24(12):1904-18.

19. McCormack B, McCance TV. Development of a framework for personcentred nursing. J Adv Nur. 2006;56(5):472-9. 
20. Vassbø TK, Bergland Å, Kirkevold M, Lindkvist M, Lood Q, Sandman PO, et al Effects of a person-centred and thriving-promoting intervention on nursing home staff job satisfaction: a multi-Centre, non-equivalent controlled before-after study. Nurs Open. 2020;7(6):1787-97.

21. Brooker DJ, Woolley RJ. Enriching opportunities for people living with dementia: the development of a blueprint for a sustainable activity-based model. Aging Ment Health. 2007;11(4):371-83.

22. Jeon YH, Luscombe G, Chenoweth L, Stein-Parbury J, Brodaty H, King M, et al. Staff outcomes from the caring for aged dementia care resident study (CADRES): a cluster randomised trial. Int J Nurs Stud. 2012:49(5):508-18.

23. Rokstad AM, Vatne S, Engedal K, Selbaek G. The role of leadership in the implementation of person-centred care using dementia care mapping: a study in three nursing homes. J Nurs Manag. 2015;23(1):15-26.

24. Rosemond CA, Hanson LC, Ennett ST, Schenck AP, Weiner BJ. Implementing person-centered care in nursing homes. Health Care Manag Rev. 2012;37(3): 257-66

25. Rosvik J, Kirkevold M, Engedal K, Brooker D, Kirkevold O. A model for using the VIPS framework for person-centred care for persons with dementia in nursing homes: a qualitative evaluative study. Int J Older People Nursing. 2011;6(3):227-36

26. Stein-Parbury J, Chenoweth $\mathrm{L}$, Jeon $\mathrm{YH}$, Brodaty $\mathrm{H}$, Haas $\mathrm{M}$, Norman $\mathrm{R}$. Implementing person-centered care in residential dementia care. Clin Gerontol. 2012;35(5):404-24.

27. Backman A, Ahnlund P, Sjogren K, Lovheim H, McGilton KS, Edvardsson D. Embodying person-centred being and doing: leading towards personcentred care in nursing homes as narrated by managers. J Clin Nurs. 2020; 29(1-2):172-83.

28. Backman A, Sjogren K, Lindkvist M, Lovheim H, Edvardsson D. Towards person-centredness in aged care - exploring the impact of leadership. J Nurs Manag. 2016;74:766-74.

29. Backman A, Sjogren K, Lindkvist M, Lovheim H, Edvardsson D. Characteristics of highly rated leadership in nursing homes using item response theory. J Adv Nurs. 2017;73:2903-13

30. Edvardsson D, Backman A, Bergland A, Björk S, Bölenius K, Kirkevold M, et al. The Umeå ageing and health research programme (U-age): exploring person-centred care and health-promoting living conditions for an ageing population. Nord J Nurs Res. 2016;36:168-74.

31. NBHW, National Board of Health and Welfare. Socialstyrelsen- Öppna jämförelser 2018-Vård och omsorg om äldre. In: Jämförelser mellan kommuner och län (In Swedish). https://www.socialstyrelsen.se/globalassets/ sharepoint-dokument/artikelkatalog/oppna-jamforelser/2019-2-2.pdf. 2018. Accessed Oct 102020.

32. Bjork $S$, Juthberg $C$, Lindkvist $M$, Wimo A, Sandman PO, Winblad B, et al. Exploring the prevalence and variance of cognitive impairment, pain, neuropsychiatric symptoms and ADL dependency among persons living in nursing homes; a cross-sectional study. BMC Geriatr. 2016;16:154.

33. Ekvall G, Arvonen J. Leadership profiles, situation and Effectiviness. Creat Innov Manag. 1994;3:139-61.

34. Ekvall G, Arvonen J. Change-centered leadership: an extension of the twodimensional model. Scand J Manag. 1991;7(1):17-26.

35. Edvardsson D, Fetherstonhaugh D, Nay R, Gibson S. Development and initial testing of the person-centered care assessment tool (P-CAT). Int Psychoger. 2010;22(1):101-8.

36. Sjogren $K$, Lindkvist M, Sandman PO, Zingmark K, Edvardsson D. Psychometric evaluation of the Swedish version of the person-centered care assessment tool (P-CAT). Int Psychoger. 2012;24(3):406-15.

37. Shrive FM, Stuart $H$, Quan $H$, Ghali WA. Dealing with missing data in a multi-question depression scale: a comparison of imputation methods. BMC Med Res Methodol. 2006;6:57.

38. Pallant J. SPSS survival manual. England: Open University Press; 2013.

39. Bollig G, Schmidt G, Rosland JH, Heller A. Ethical challenges in nursing homesstaff's opinions and experiences with systematic ethics meetings with participation of residents' relatives. Scand J Caring Sci. 2015;29(4):810-23.

40. Dahlqvist V, Eriksson S, Glasberg A-L, Lindahl E, Lützén K, Strandberg G, et al. Nurs Ethics. 2007;14(2):181-93.

41. Juthberg C, Sundin K. Registered nurses' and nurse assistants' lived experience of troubled conscience in their work in elderly care-a phenomenological hermeneutic study. Int J Nurs Stud. 2010;47(1):20-9.

42. Ericson-Lidman E, Strandberg G. Dealing with troubled conscience in municipal care of older people. Nurs Ethics. 2013:20(3):300-11.
43. Gustafsson G, Eriksson S, Strandberg G, Norberg A. Burnout and perceptions of conscience among health care personnel: a pilot study. Nurs Ethics. 2010; 17(1):23-38

44. Devik SA, Munkeby H, Finnanger M, Moe A. Nurse managers' perspectives on working with everyday ethics in long-term care. Nurs Ethics. 2020;27(8): 1669-80.

45. Jokwiro Y, Rickard N, Edvardsson D. Factors associated with stress of conscience in caring for older people with delirium in a hospital setting: an exploratory cross-sectional study. Collegian. 2020;28:296-302.

46. Edvardsson D, Sandman P, Borell L. Implementing national guidelines for person-centered care of people with dementia in residential aged care: effects on perceived person-centeredness, staff strain, and stress of conscience. Int Psychoger. 2014;26(07):1171-9.

47. Vernooij-Dasssen MJ, Faber MJ, Rikkert MG, Koopmans RT, van Achterberg T, Braat DD, et al. Dementia care and labour market: the role of job satisfaction. Aging Ment Health. 2009;13(3):383-90.

48. Jokwiro Y, Pascoe E, Edvardsson K, Rahman MA, McDonald E, Lood Q, et al. Stress of conscience questionnaire (SCQ): exploring dimensionality and psychometric properties at a tertiary hospital in Australia. BMC Psychol. 2020:8(1):1-10.

\section{Publisher's Note}

Springer Nature remains neutral with regard to jurisdictional claims in published maps and institutional affiliations.
Ready to submit your research? Choose BMC and benefit from:

- fast, convenient online submission

- thorough peer review by experienced researchers in your field

- rapid publication on acceptance

- support for research data, including large and complex data types

- gold Open Access which fosters wider collaboration and increased citations

- maximum visibility for your research: over $100 \mathrm{M}$ website views per year

At BMC, research is always in progress.

Learn more biomedcentral.com/submissions 